\title{
"Sentir-se em casa longe de casa": vulnerabilidade, religiosidade e apoio social entre os migrantes brasileiros no Japão
}

\author{
"Being home away from home": vulnerability, religiosity \\ and social support among Brazilian migrants in Japan
}

Regina Yoshie Matsue ${ }^{1}$

${ }^{1}$ Centro de Ciências da Saúde, Mestrado em Saúde Coletiva, Universidade de Fortaleza. Avenida

Washington Soares 1321,

Edson Queiroz. 60811-905

Fortaleza CE.

rymatsue08@yahoo.com
Abstract This paper analyzes the role of religiosity and the impact of social support in the lives of Brazilian migrants in Japan. Despite being in Japan for over two decades, the Brazilians are not integrated into the local society. This social alienation has a negative effect on the health of the migrants, making them prone to mental and physical distress. The lack of language skills prevents the migrants from looking for professional help, and even if they seek for it they cannot express themselves properly. In this context, the migrants found support among their compatriots and religious groups. This essay is based on ethnographic research carried out in Japan between 2003 and 2006 and focuses on the work and activities of the Catholics among the Brazilian migrants. The data collection was based on 15 semi-structured interviews, which were conducted among the members. Besides the religious support, the group offers the migrants a social support space for their daily lives in Japan. Therefore, the group represents a place of socialization and social support for many Brazilians, which helps them to overcome their feelings of vulnerability. The ecclesiastic power, on the other hand, regulates the migrants' behavior through an ethos and a world view legitimized by the group.

Key words Migrant, Religion, Vulnerability and social support
Resumo Este artigo busca analisar o papel da religiosidade e o impacto da rede de apoio social na vida dos migrantes brasileiros no Japão. Apesar dos brasileiros estarem no Japão por aproximadamente duas décadas, estes não se integraram à sociedade japonesa. Este estado de alienação social na sociedade japonesa exerce um efeito negativo sobre nas condições de saúde dos migrantes, tornando-os vulneráveis a distúrbios físicos e mentais. Eles se sentem encurralados, pois mesmo que busquem ajuda de profissionais da saúde a falta de fluência na lingua japonesa os impedem de se expressarem corretamente. Neste contexto os migrantes buscam apoio e solidariedade entre seus compatriotas e nos grupos religiosos. Este estudo foi baseado em um trabalho etnográfico realizado no Japão no período de janeiro de 2003 a dezembro de 2006, e enfocou as atividades de um grupo de católicos entre os brasileiros no Japão. No total foram realizadas 15 entrevistas com os membros. Veremos que os migrantes encontram no grupo além de serviços religiosos uma rede de apoio social que os ajudam a lidar com o sentimento de vulnerabilidade. Entretanto, por trás desta atividade de orientação e apoio religioso existe um poder eclesiástico que, indiretamente, controla a conduta pessoal e moral e exerce uma ação regulatória na vida dos migrantes.

Palavras-chave Migrante, Religião, Vulnerabilidade e apoio social 


\section{Introdução}

A severa crise econômica enfrentada pelo Brasil no final da década de oitenta, aliada à escassez de mão-de-obra do setor manufatureiro no Japão provocou um grande movimento migratório de trabalhadores nipo-brasileiros para este país. Fenômeno conhecido como "migração de retorno" ou "fenômeno dekasségui", que se tornou tópico de várias pesquisas acadêmicas realizados por brasileiros e estrangeiros de diversas áreas. Tais estudos mostram os problemas enfrentados por esses migrantes e a posterior formação e marginalização da comunidade brasileira no Japão ${ }^{1-4}$. Alguns estudos apontam também a relação entre migração e saúde, particularmente distúrbios mentais ${ }^{5,6}$, devido às condições estressantes inerentes ao trabalho, ao processo adaptativo e à posterior marginalização na sociedade local. Porém, são inexistentes estudos que reflitam sobre o impacto das redes de apoio social e religiosidade no bem-estar destes os migrantes.

Desde o início do processo migratório, os brasileiros no Japão organizaram-se entre si em busca de formas alternativas de socialização ou de serviços. A comunidade brasileira tem forte presença em algumas cidades como em Oizumi e Hamamatsu onde representa dez por cento da população local ${ }^{2,3}$, e em muitas outras cidades de diversas localidades e regiões do Japão.

Por um lado, a rede criada por estas comunidades simplifica a vida dos decasséguis, oferecendo serviços diversos, restaurantes e lojas de produtos brasileiros. Mas por outro lado, os brasileiros tende a viver isolados em suas comunidades, sem muito contato e apoio da sociedade local. Neste contexto, os migrantes buscam refúgio e formas de enfrentamento para seus problemas nas atividades religiosas oferecidas por vários grupos religiosos tais como os católicos, protestantes, evangélicos e das novas religiões japonesas, dentre outros.

Este trabalho é parte dos resultados obtidos na tese de doutoramento do autor ${ }^{7}$ tem como objetivo analisar a relação entre práticas religiosas e bem-estar a partir das atividades desenvolvidas pelo grupo de católicos entre os brasileiros no Japão.

No final dos anos oitenta, o contingente migratório era composto por cidadãos japoneses que haviam migrado para o Brasil no pós-guerra e seus filhos que ainda possuíam a nacionalidade japonesa. Pois, como é sabido, até 1990 o Japão não aceitava legalmente trabalhadores estrangeiros não especializados para trabalhar em seu território. Mas devido à escassez de mão-deobra para a indústria manufatureira o governo japonês muda a lei em 1990. A partir desta data o Japão começou a permitir a entrada dos filhos de japoneses da segunda geração (nisseis) que passam a ter direito ao visto por três anos e de um ano para os de terceira geração (sanseis) ambos renováveis. Muitos descendentes iniciaram então um processo migratório massivo, pois este visto dá o direito a eles de residirem e trabalharem no Japão por tempo indeterminado.

Esta lei, porém, inspira um debate controverso uma vez que é baseada ainda no discurso de homogeneidade racial da nação japonesa. Por um lado, se aceita os descendentes de japoneses pelo fato pertencerem a uma linhagem familiar japonesa ainda que seja um vínculo distante. Laços familiares são baseados em laços de sangue, e em muitos discursos de políticos japoneses que apoiaram esta lei podemos verificar a alusão aos laços de consanguinidade com os filhos e netos de japoneses nascidos no exterior ${ }^{2,9}$. Desta forma, a ideologia de homogeneidade racial é mantida ao mesmo tempo em que se encontra uma forma de aliviar o problema da deficiência de mão-de-obra. Por outro lado, a política de aceitação dos trabalhadores nipo-brasileiros no Japão como uma forma de manter o ideal de homogeneidade racial se torna contraditória.

De acordo com as teorias sobre a niponicidade (nihonjinron) o ser japonês é definido por quatro critérios: raça, sangue, cultura e língua ${ }^{10}$. Os nipo-brasileiros preenchem os dois requisitos iniciais, mas pecam por serem culturalmente brasileiros e por não possuírem o domínio do idioma japonês como esperado. Desta forma, muitos descendentes de japoneses, que se consideravam "japoneses nos Brasil" e que possuem fortes vínculos à terra étnica e imaginária de seus ancestrais, são rejeitados no Japão. A partir daí o processo se inverte e estes começam a se identificar fortemente com o Brasil no Japão. Devido a esta "inversão" de posição muitos pesquisadores classificam os migrantes brasileiros no Japão como uma minoria "duplamente marginalizada" ou uma diáspora dupla ${ }^{11}$. Estes são considerados como "japoneses no Brasil", e, mais recentemente, como "brasileiros no Japão".

\section{Metodologia}

O trabalho tem um enfoque qualitativo e baseiase no modelo etnográfico. A pesquisa de campo, que inclui o processo de observação participante 
das várias atividades e celebrações do grupo e entrevistas com praticantes e missionários, foi realizada sistematicamente no período de janeiro de 2003 a dezembro de 2006 na Diocese de Saitama. Esta diocese abrange as províncias de Saitama e de Gunma onde se localizam as cidades de Oizumi e Ota, que são locais com grande concentração de brasileiros ${ }^{4}$. E também inclui as províncias de Tochigi e Ibaraki, onde há pequenas e esparsas comunidades de brasileiros. $\mathrm{Na}$ região, há aproximadamente doze igrejas que oferecem missa e ofícios religiosos em língua portuguesa, na qual residem aproximadamente trinta mil católicos brasileiros ${ }^{8}$.

Utilizamos também a entrevista semiestruturada como técnica de coleta de dados. No total foram realizadas quinze com os membros católicos. Vale destacar que as entrevistas foram realizadas entre os que são assíduos frequentadores das atividades e dos serviços em português oferecidos pelas paróquias no Japão. As missas têm uma participação média de cinquenta a sessenta pessoas, e somente vinte por cento deste montante são membros que colaboram ativamente nas atividades da comunidade.

Com o intuito de apreender as experiências, as buscas e os sentidos da prática religiosa no contexto dos migrantes brasileiros no Japão as entrevistas foram realizadas individualmente e em profundidade. Consideramos esta técnica dinâmica e flexível, sendo útil para a apreensão de uma realidade tanto para tratar de questões relacionadas ao íntimo do entrevistado, como para a descrição de processos complexos nos quais está envolvido. As entrevistas buscaram esclarecer a importância da prática religiosa para os migrantes, sendo seu conteúdo interpretado e contextualizado à luz da teoria antropológica e do apoio social.

\section{Contextualização dos sujeitos da pesquisa}

Estima-se que aproximadamente trezentos mil brasileiros vivem e trabalham no Japão ${ }^{12}$. A maioria dos trabalhadores brasileiros no Japão provém da classe média, sendo que no Brasil eles trabalhavam como profissionais liberais ou em seus próprios negócios. No Japão, porém, mais de noventa por cento dos migrantes se tornam invariavelmente operários de montadoras ou de linha de produção ${ }^{6}$ (independente da posição social ou profissão exercida anteriormente).

Os migrantes brasileiros realizam um tipo de trabalho totalmente impessoal, mecânico e repetitivo. Este tipo de trabalho é estigmatizado pelos três ks kiken (perigoso), kitsui (árduo) kitanai $(\text { sujo })^{2}$, que sendo desprezado pelos trabalhadores japoneses é realizado por cidadãos de segunda categoria e ou migrantes. Esta situação de trabalho aliado ao estado de liminaridade social, no qual os migrantes vivem entre dois países sem efetivamente participar da vida social de ambos, causa um sentimento de desenraizamento ${ }^{6}$.

Os migrantes se tornam então, encurralados em uma situação de anomia social ${ }^{13}$, onde as normas, os valores e os códigos socioculturais do país de origem não têm mais força nem relevância no novo contexto. E, ao mesmo tempo, os valores culturais do país receptor não foram adotados por estes. Assim, os sentidos dos valores culturais e de vida se tornam confusos ou se perdem no contexto migratório, deixando uma espécie de vazio no qual a sociedade não consegue mais exercer controle sobre os seus membros, deixando-os a mercê de si mesmos.

A maioria destes migrantes se encontra em um processo de migração circular ${ }^{14}$ entre o Brasil e o Japão, onde a readaptação em ambos os países é difícil. Outros já vivem mais de quinze anos no país com o visto de permanência. Recentemente, a tendência dos brasileiros de permanecer no território japonês vem trazendo uma série de implicações com relação ao status socioeconômico e político e o futuro destes migrantes e suas famílias. Onde questões de cidadania, saúde, educação, e participação social e política se tornam prementes. Porém, os planos de muitos destes brasileiros foram minados a partir da deflagração da crise econômica mundial em 2008. Em fevereiro de 2009 estimava-se que aproximadamente quinze por cento dos brasileiros que viviam no Japão ou estavam sob a ameaça de perder o emprego, ou tiveram seus salários reduzidos ou já estavam desempregados ${ }^{15}$.

\section{Referencial Teórico}

Os trabalhadores brasileiros no Japão pejorativamente se auto identificam como peças de uma engrenagem que não pode parar, ou robôs que fazem o trabalho mecanicamente. Seguindo a concepção marxista, este modo de produção caracteriza uma experiência de trabalho profundamente alienadora ${ }^{16}$. Pois, o sentido deste se perde no processo produtivo, uma vez que o produto final do trabalho não pertence ao trabalhador e sim se torna uma mercadoria de troca. O trabalho se torna impessoal e mecânico, pois não há como estabelecer uma relação de identidade com o mesmo. 
Aliado a esta característica inerente do sistema produtivo, os trabalhadores brasileiros vivenciam ainda a dificuldade de se expressar. Muitas vezes, estes se sentem frustrados, impotentes e incapazes de colocar suas opiniões e sugestões devido à barreira da língua e à discriminação que sofrem no ambiente de trabalho ${ }^{6}$. Isolar-se socialmente, sem ter com quem conversar de uma forma íntima, pode representar um perigo para a saúde tão sério quanto à obesidade, a falta de exercício físico ou as altas taxas de colesterol ${ }^{17}$.

Este estado de anomia e alienação social exercem um efeito negativo sobre as condições de saúde do migrante, tornando-os vulneráveis a problemas de saúde variados e transtornos mentais. Estudos indicam que pelo menos três por cento dos migrantes são diagnosticados com problemas de depressão e distúrbios mentais ${ }^{5,6}$. E, mesmo que estes buscassem ajuda de um profissional da saúde, a dificuldade com a língua japonesa os impediria de se expressar corretamente.

Entretanto, a perspectiva para o futuro se torna sombria para grande parte destes migrantes, pois, estando afastados geograficamente por longos anos do Brasil fica difícil a perspectiva de volta e de emprego no país. Ao mesmo tempo, as condições e a oferta de trabalho no Japão se tornaram escassas. Novamente é uma situação de dupla alienação, desta vez econômica. Esta situação gera mais estresse, acarretando uma queda na qualidade de vida destes migrantes.

Estudos mostram que o aparecimento de transtornos físicos e psíquicos estão profundamente relacionados com as emoções e o sentimento de vulnerabilidade ${ }^{17,18}$. Esta perspectiva reflete uma concepção holística em saúde, ou seja, não há uma separação entre o que chamamos de transtornos físicos e psiquicos, ou corpo e mente, uma vez que consideramos a importância das emoções humanas e como ela age tanto no cérebro como no corpo ${ }^{19}$. Esta abordagem vai além da concepção cartesiansa que separa mente e corpo; a mente é parte do cérebro que é parte do corpo e as duas partes interagem em um organismo integrado e singular ${ }^{20}$.

Baseada nesta concepção da unidade entre corpo/mente que considera os reflexos das emoções na saúde, a teoria do apoio social desenvolvida por Valla ${ }^{17,18}$ propõe que o início de uma doença pode estar relacionado a uma reação emocional desequilibrada do homem, causada frequentemente pelo que se chama genericamente de estresse por se sentir ameaçado em seu ambiente. Nesta perspectiva, o trabalho remunerado somado à estrutura temporal do cotidi- ano, contatos com pessoas fora da família, manutenção da identidade e status contribuem para a manutenção dos eixos de organização do viver cotidiano, primordiais ao bem estar físico e mental do ser humano ${ }^{21}$, sendo que a ameaça a qualquer um destes eixos representa sérias ameaças à saúde e ao bem estar do mesmo.

Como vislumbrar alternativas nesta situação de impasse em que vive o migrante brasileiro no Japão? Neste contexto, os migrantes encontram apoio e solidariedade entre seus pares, familiares, grupo de amigos, e na comunidade brasileira em geral. Assim, foram surgindo os "pequenos brasis" à margem da sociedade japone$\mathrm{sa}^{1,2,6,12}$. A proposta central do apoio social é de as pessoas sentirem que contam com o apoio de um grupo de pessoas (associação comunitária, família, vizinhança, igreja, entre outros), o qual tem o efeito de causar uma melhoria na saúde dos envolvidos ${ }^{17,18}$, pois o sentimento de vulnerabilidade é vencido e o indivíduo se sente fortalecido dentro do grupo ${ }^{22}$.

De acordo com Valla ${ }^{17,18}$ não só a origem da doença, mas também a sua resolução está diretamente relacionada às emoções. Desta forma, o poder terapêutico pode ser exercido através da influência direta nas emoções, no comportamento e na cognição das pessoas envolvidas. A crença em algo divino e a visão de mundo baseada na doutrina e na fé dão mais sentido e coerência à vida, e, sobretudo, dá suporte emocional para o enfrentamento de situações críticas ${ }^{22,23}$.

O papel da religião como potencial promotora de bem estar de um grupo pode ser analisada através de três abordagens: do cuidado e prevenção, do poder terapêutico e do empoderamento comunitário ${ }^{24}$. As atividades preventivas estão relacionadas com o lado pessoal (crises e conflitos pessoais), familiares e sociais (delinquência juvenil, violência, etc.). Os grupos religiosos podem oferecer suporte para o indíviduo e a sua família, orientando na educação dos filhos, na manutenção de valores e no acesso para serviços comunitários.

Entretanto, não podemos deixar de mencionar que por trás desta atividade de orientação e apoio, seja espiritual ou material, existe toda uma estrutura eclesiástica que exerce um poder que, indiretamente, controla a conduta pessoal e moral dos membros. Há, por parte dos grupos religiosos, uma ação regulatória das ações e das capacidades do sujeito dentro de um éthos e de uma visão de mundo legitimada pelo grupo ${ }^{25}$. Por um lado, os sujeitos reconstroem suas vidas e identidades baseados em uma determinada te- 
odiceia, dando uma ressignificação ao problema vivido $^{26}$. Por outro lado, o grupo reinvindica certo controle das ações dos indivíduos, mobilizando os membros para que defendam e difundam tais valores e ideias.

Tais argumentos, de acordo com a teoria do apoio social, não invalidam a importância que os grupos religiosos exercem na promoção de saúde de determinada população ${ }^{18,22}$. Assim, é indubitável que a afiliação religiosa pode promover a consciência social do grupo ao mobilizar recursos humanos e institucionais a favor de valores culturais alternativos, favorecendo um empoderamento comunitário. Como veremos a seguir, o grupo religioso exerce um papel importante na vida dos migrantes, por ser o local por excelência de rede de apoio e participação comunitária.

\section{Resultados e discussão}

Neste artigo limitamo-nos a examinar as atividades do grupo católico entre os brasileiros no Japão. Até o final dos anos oitenta, o número de católicos no Japão era relativamente pequeno, representando menos de um por cento da população do país. Contudo, com a chegada de estrangeiros de países católicos nos últimos anos, o número de católicos no Japão dobrou ${ }^{8}$. Por um lado, a Igreja Católica tem visto nos migrantes uma possibilidade de crescimento inimaginável há algumas décadas atrás. Com a vinda de muitos migrantes de países católicos tais como Brasil, Peru e Filipinas, houve também um aumento na demanda por assistência e serviços nas paróquias locais das igrejas do Japão.

Por outro lado, a aceitação e a participação de estrangeiros nas paróquias locais ainda é problemática. Devido à própria história de proibição e perseguição sofrida pelo Catolicismo no passado $^{27}$, aliada à mentalidade de grupo ${ }^{10}-$ dificuldade em aceitar o "diferente" - as comunidades católicas no Japão são fechadas em si mesmas e avessas à abertura e às mudanças. Para a população local, a participação de grupos de estrangeiros nas paróquias é tida como uma "invasão"28. Desta forma, apesar dos migrantes estarem ocupando os assentos vazios nas igrejas que geralmente possuem poucos fiéis e têm dificuldade de atrair jovens ou novos integrantes japoneses -, os migrantes são menosprezados e tratados como "visitantes" pela comunidade local. Tendo em vista este cenário, os brasileiros preferem reunir-se entre eles, evitando qualquer contato com as comunidades locais. Esta situa- ção levou à criação de comunidades distintas e separadas nas paróquias locais.

- Nós brasileiros admiramos a forma disciplinada em que os japoneses realizam a missa deles. Não há crianças fazendo barulho, as músicas são tocadas em órgão, tudo muito organizado. Porém, a gente não se sente à vontade, pois sabemos que os japoneses se incomodam com nossa bagunça. Nós gostamos mesmo é da música cantada ao som do violão, das crianças correndo e fazendo barulho... É nossa forma de sentirmos em casa, mesmo no Japão (membro da comunidade de Tsuchiura, janeiro/2004).

Atualmente, em locais com grande concentração de brasileiros no Japão, as igrejas católicas realizam missas em português mensalmente e também oferecem serviços tais como batismo, cursos de catecismo, primeira comunhão e crisma para crianças e adultos. Através de celebrações dos rituais festivos do calendário católico e da incorporação das festividades do catolicismo popular brasileiro, tais como as festa juninas, os brasileiros vêm ganhando espaço nas igrejas locais. As igrejas representam, então, espaços ímpares de socialização e de manutenção da identidade do grupo. Vale destacar que a grande maioria dos católicos brasileiros no Japão busca na igreja apoio e sentidos que orientem suas vidas nos momentos críticos.

- Eu não tinha contato nenhum com o Japão até o meu casamento, meu marido é que é descendente, ele entende e fala japonês. Quando eu cheguei aqui foi um choque grande, pois tudo é muito diferente e para piorar eu ficava trancada dentro de casa. Eu não trabalhei por dois anos por causa da dificuldade com a lingua e por causa das minhas duas filhas que eram pequenas. Neste período meu pai faleceu no Brasil, foi muito triste, eu não tinha como ir no funeral dele, me senti muito triste e entrei em depressão... Foi daí que procurei a igreja para poder rezar um pouco por ele e conversar com o padre brasileiro, foi minha salvação, pois me senti acolhida e comecei a melhorar, a partir de então comecei a participar das missas e levei minhas filhas para fazer o catecismo. (membro da comunidade de Tsuchiura, dezembro/2004).

- Dois anos após chegar aqui no Japão, meu marido e eu resolvemos abrir um restaurante, os negócios corriam bem, mas com o tempo acumulamos algumas dividas e falimos, meu marido entrou em depressão e começou a beber muito, foi uma fase horrível... Estávamos sem emprego e o único lugar que eu conseguia encontrar um pouco de paz era na igreja, e foi lá também que encontramos um conhecido que trabalhava como agenciador de 
empregos que se tornou nosso contato para conseguirmos um novo emprego. Foi assim que enxergamos uma luz no final do túnel. (membro da comunidade de Tomobe, dezembro/2004).

Os migrantes percebem as igrejas como o lugar de refúgio, onde eles podem receber suporte espiritual e ou emocional. E também material, pois através de uma rede de conexão que se cria em torno das igrejas, os migrantes trocam informações sobre trabalho, moradia e diversos assuntos de interesse geral, representando um canal por meio do qual muitos se adaptam ao novo local ${ }^{29}$.

As práticas religiosas representam então formas solidárias e alternativas de enfrentamento da situação em que se encontra o migrante. Desta forma, como explícito nas falas, o apoio social oferecido pelos grupos religiosos pode ser tangível como as formas de ajuda material ou física, ou intangível por meio de apoio emocional ou psicológico $^{24}$. No contexto dos brasileiros no Japão, muitos grupos religiosos assumem o papel do mobilizador social, sendo o local de socialização, redes de contato, assistência social e aconselhamento que os migrantes não encontram nos órgãos oficiais de migração. A certeza de que se pode contar com o auxílio do outro é a questão central do apoio social ${ }^{18,22}$. Funciona como uma espécie de amortecedor contra os efeitos nocivos de eventos estressantes e inesperados da vida.

Outra questão que emerge nas falas dos entrevistados é a preocupação com a educação dos filhos que os impele a buscar apoio nas paróquias. Para muitos migrantes, os valores, as práticas e a fé católicas representam a base da orientação familiar. O motivo maior para muitas famílias estarem engajadas nas atividades da igreja reflete uma preocupação com a orientação e educação moral e religiosa dos filhos que estão sendo educados no Japão.

- Eu fui criada dentro da comunidade católica no Brasil e minha mãe era praticante fervorosa [...]. Quando eu cheguei aqui, eu me sentia isolada de todos e fiquei muito preocupada com a educação dos meus filhos. Mas graças a Deus eu encontrei logo um grupo de brasileiros na igreja que me ajudavam na orientação das minhas crianças, pois elas precisam aprender o que é certo e errado, a respeitar o próximo e ter solidariedade uns com os outros. Eu não consigo imaginar minha vida sem a minha fé. Deus me livre se meus filhos crescessem como os japoneses, sem religião! É por isso que eu quero preservar minha crença e passá-la para meus filhos. As duas mais velhas já terminaram a primeira comunhão e agora o mais novo está come- çando. Eles cresceram no Japão, mas sabem que são brasileiros e eu quero manter a tradição. (membro da comunidade de Tsuchiura, junho/2005).

Nesta perspectiva, a religiosidade está associada também à identidade do grupo, sendo que o catolicismo representa a base sobre a qual os migrantes constroem a diferença entre "ser brasileiro" e "ser japonês" na geração dos filhos. Para muitos, "ser católico é sinônimo de ser brasileiro", representando um forte instrumento de diferenciação, identidade, sentido e, ao mesmo tempo, de orientação moral e espiritual.

Baseada em seu ethos católico, a entrevistada conclui que os “japoneses não tem religião". Vale lembrar, porém, que isso não significa que eles não possuam suas crenças e sigam seus rituais, mas sim que estes não são católicos e, consequentemente, os ideais católicos não fazem parte da visão de mundo destes (a religiosidade da população japonesa é pautada em um misto de princípios taoístas, budistas e xintoístas). Desta forma, para muitos brasileiros, o catolicismo implica na manutenção da identidade brasileira, o que dá sentido e orientação às suas vidas e de seus familiares e os diferenciam dos japoneses. Assim, as crianças são incentivadas a seguir uma orientação católica onde as aulas de catecismo e de primeira comunhão são ministradas em português. Lembramos que a maioria das crianças brasileiras educadas no Japão já não possui fluência na língua portuguesa, pois, devido à pressão assimilacionista sofrida nas escolas japonesas, elas não são estimuladas a aprender a língua materna ${ }^{30,31}$.

Percebendo a situação de marginalização social em que se encontram os migrantes, a igreja promove os valores católicos na vida familiar e em suas atividades. Os brasileiros católicos optam em seguir a orientação da igreja, esta por sua vez, exerce uma ação regulatória na conduta destes.

A partir das entrevistas podemos observar que os brasileiros agem de acordo com valores culturais e religiosos que remetem às suas experiências vividas no país de origem. Tais valores que foram internalizados a partir de uma socialização em família e por uma educação de orientação católica, são reforçados pelas atividades da igreja no Japão, tornando-se a base para a reconstrução da identidade, ou seja, afirmação da posição do indivíduo na nova realidade em que vivem $^{25}$. Assim sendo, os migrantes reconstroem e resignificam suas vidas a partir de uma abordagem católica. O grupo, entretanto, reivindica certo controle das ações destes migrantes, mobilizando-os membros para que defendam e difundam tais valores e ideias. 
Adicionalmente, a igreja divulga seu espaço como sendo o locus de mobilização e de reconhecimento social dos migrantes pela sociedade receptora, como veremos adiante. Durante o período de pesquisa de campo observamos a realização de festas juninas em diversas comunidades. Dentre elas destacaram-se as festas da igreja da cidade de Kazo localizada na província de Saitama e da cidade de Moka na província de Tochigi. Estas duas paróquias organizaram com destaque, por mais de quatro anos consecutivos, festas juninas com a participação e o envolvimento em conjunto das comunidades brasileira e japonesa. Como exemplo, podemos citar a festa junina realizada em 27 de junho de 2004 na cidade Moka (na província de Tochigi). O evento teve o apoio da província local e foi noticiada no programa da rede nacional de televisão NKH Ohayou Nippon (Bom Dia Japão), semanas antes do evento, como um matsuri (festival) local em uma tentativa de atrair visitantes para a pequena cidade. $\mathrm{O}$ evento conseguiu trazer mais de dois mil e quinhentos visitantes, a maior parte, brasileiros e alguns japoneses residentes na região.

A partir de sucessivas festas juninas bem sucedidas, os esforços dos membros brasileiros destas comunidades católicas começaram as ser reconhecidos pelos japoneses.

- No início, os japoneses não gostavam de nós, diziam que éramos barulhentos e que faziamos muita bagunça na igreja, daí agente nunca se reunia com eles. Mas a partir da realização das festas, eles começaram a perceber que nosso jeito de organizar as coisas é mais relaxado, a gente brinca e trabalha ao mesmo tempo, mas funciona. Nossa igreja tem poucos membros japoneses e estávamos com dificuldades financeiras. Por quatro anos consecutivos, devido à festa junina, conseguimos arrecadar o dobro do que os japoneses levariam para arrecadar normalmente durante o ano todo! Agora eles estão satisfeitos com a nossa presença... (membro da comunidade de Moka, agosto/2004).

De acordo com o depoimento dos brasileiros envolvidos na organização da festa junina, a comunicação e a interação entre as duas comunidades melhoraram a partir do resultado positivo do evento.

- A festa abriu as portas da igreja para a comunidade brasileira, agora podemos frequentar e organizar as nossas atividades na igreja. A comunicação entre nós e os japoneses ainda não é ideal, mas melhorou bastante. Há os que são mais fechados, mas temos agora várias famílias japonesas que participam das nossas festas e atividades (membro da comunidade de Moka, agosto/2004).
A festa tornou-se um símbolo de identidade e de orgulho da comunidade brasileira, gerando autoestima e coesão no grupo. Muitos foram motivados a continuarem envolvidos nos eventos da igreja como uma forma de conquistar espaço social e visibilidade. Assim, a igreja se torna o locus por excelência da vida comunitária, normatizando e regulando as ações ${ }^{23}$ da vida comunitária entre os migrantes.

\section{Considerações Finais}

Neste artigo buscamos refletir sobre o papel da religiosidade e da rede de apoio social na vida dos migrantes brasileiros no Japão. Vimos que, de forma geral, estes vivem em um estado de anomia social dentro da sociedade japonesa e, sendo assim, encontram formas alternativas de organização social dentro de suas próprias comunidades, como, por exemplo, há o grupo católico representando um ponto de referência para muitos brasileiros. Apesar destes encontrarem barreiras com relação à sua aceitação pela comunidade católica local, os mesmos formaram sua própria rede de membros e assim foram encontrando espaço dentro das igrejas locais.

As práticas religiosas, aliadas ao poder de coesão do grupo, representam desta maneira formas solidárias e criativas de lidar com as dificuldades do dia-a-dia. A certeza de poder contar com o apoio do grupo gera bem-estar e conforto para os migrantes que vivem em um ambiente incerto na sociedade receptora. Assim, a busca da religiosidade pelos migrantes denota três imperativos: busca por apoio social material e/ou emocional, orientação na educação dos filhos e a necessidade de afirmação da identidade.

Vimos que a igreja representa um local de socialização para os migrantes e um espaço legítimo para realizar suas atividades e de empoderamento comunitário. Podemos perceber, entretanto, a autoridade social que o grupo exerce sobre as famílias dos migrantes, orientando e normatizando suas ações a partir de uma visão de mundo católica. Ao mesmo tempo em que oferece diversos serviços à comunidade, mobiliza a ação dos migrantes para a divulgação e a manutenção dos valores e das tradições católicas. Há entre os migrantes e a igreja uma relação de responsabilidade mútua, de abertura e de acolhida, onde as duas partes envolvidas se unem buscando fortalecer seus interesses no contexto da sociedade japonesa. 


\section{Referências}

1. Linger D. No One Home. Stanford: Stanford University Press; 2001.

2. Roth J. Brokered Homeland: Japanese Brazilian Migrants in Japan. New York: Cornell University Press; 2002.

3. Lesser J, editor. Searching for Home Abroad: Japanese Brazilians and Transnationalism. Durham and London: Duke University Press; 2003.

4. Tsuda T, editor. Local Citizenship in recent Countries of Immigration. New York, Oxford: Lexington Books; 2006.

5. Miyasaka L, Canasiro S, Abe Y, Otsuka K, Tsuji K, Hayashi T, Andreoli S, Nakagawa D, Shirakawa I, Atallah A, Kato S. Migration and Mental Health: Japanese Brazilians in Japan and in Brazil. J Bras. Psiquiatr. 2007; 56(1):48-52.

6. Tsuda T. Homeland-less Abroad: Transnational Liminarity, Social Alienation, and Personal Malaise. In: Lesser J, editor. Searching for Home Abroad: Japanese Brazilians and Transnationalism. Durham and London: Duke University Press; 2003. p. 120-161.

7. Matsue RY. The Religious Activities among Japanese-Brazilian Dual Diaspora in Japan. In: Pratap $\mathrm{K}$, editor. Religious Pluralism in the Diaspora. Leiden: Brill; 2006. p. 121-146.

8. Statistics of the Catholic Church in Japan, 2005. [site na Internet]. [acessado 2010 fev 14]. Disponível em: http://www.cbcj.catholic.jp/jpn/data/00data.htm

9. Kajita T. The Challenge of Incorporating Foreigners in Japan: "Ethnic Japanese" and "Sociological Japanese”. In: Weiner M, Hanami T, editors. Temporary Workers or Future Citizens? London: MacMillan Press; 1998.

10. Eades J, Gill T, Befu H, editors. Globalization and Social Change in Contemporary Japan. Melbourne: Trans Pacific Press; 2000.

11. Linger D. Do Japanese Brazilians Exists? In: Lesser J, editor. Searching for Home Abroad: Japanese Brazilians and Transnationalism. Durham and London: Duke University Press; 2003. p. 201-214.

12. Costa JP. De Decasségui a Emigrante. Brasília: Funag; 2007.

13. Durkheim E. O Suicídio. São Paulo: Martin Claret; 2005.

14. Yamanaka K. I will go home, but when? Labor migration and circular diaspora formation by Japanese Brazilians in Japan. In: Douglas M, Roberts G, editors. Japan and Global migration: Foreign Workers and Advent of a Multicultural Society. Honolulu: University of Hawaii Press; 2003. p. 123-152.

15. Desemprego Interrompe Sonho Decasségui. Revista Veja Edição 2101 [revista online]. 2009 Fev 25. [acessado 2009 dez 12]. Disponível em: http:// veja.abril.com.br/250209/p_062.shtml.

16. Marx W. Alienation and Social Classes. In: Tucker R, editor. The Marx-Engels Reader. New York: W.W. Norton; 1978. p. 133-35.
17. Valla VV. Vida Religiosa como Estratégia das Classes Populares. In: Vasconcelos E, organizador. A Espiritualidade no Trabalho em Saúde. São Paulo: Editora Hucitec; 2006. p. 265-295.

18. Valla VV. Educação popular, saúde comunitária e apoio social numa conjuntura de globalização. Cad Saude Publica 1999; 15(2):7-14.

19. Hacking I. The Cartesian vision fulfilled: analogue bodies and digital minds. Interdisciplinary Science Review 2005; 30(2):153-166.

20. Damásio A. Em busca de Espinosa: prazer e dor na ciência dos sentimentos. São Paulo: Companhia das Letras; 2004.

21. Fonseca ML, Guimarães MB, Vasconcelos EM. Sofrimento Difuso e Transtornos Mentais Comuns: Uma Revisão Bibliográfica. Rev. APS 2008; 11(3):285-294.

22. Guimarães MB, Lima CM, Savi EA, Cardoso E, Valla VV, Stotz EM, Lacerda A, Santos MS. Os impasses da pobreza absoluta: a experiência da Ouvidoria Coletiva na região Leopoldina, Rio de Janeiro (RJ, Brasil). Cien Saude Colet 2011; 16(1):291-300.

23. Levin J. Deus, Fé e Saúde. São Paulo: Cultrix; 2001.

24. Maton KI, Wells EA. Religion as a Community Resource for Well-being: prevention, healing, and empowerment pathways. Journal of Social Issues 1995; 51(2):177-193.

25. Miller R, Rose N. Governing economic life. Economy and Society 1990; 19(1):1-31.

26. Berger P. The Sacred Canopy: elements of a sociological theory of religion. New York: Anchor Press Book/ Doubleday; 1967.

27. Nelson J. Myths, Missions, and Mistrust: The Fate of Christianity in $16^{\text {th }}$ and $17^{\text {th }}$ century in Japan. History and Anthropology 2002; 13(2):93-111.

28. Mira JM. Trabalhadores Latino-Americanos no Japão. In: Graduate School of Languages and Cultures. A Imigração Latino-Americana no Japão. Nagoya: Nagoya University Press; 2003. p. 143-154.

29. Ebaugh HR, Chafetz JS, editors. Religions and Migrants: Continuities and Adaptations in Immigrant Congregations. Boston: Altamira Press; 2001

30. Nukaga M. Japanese Education in an Era of Internationalization: A Case Study of an Emerging Multicultural Coexistence Model. International Journal of Japanese Sociology 2003; 12(1):79-94.

31. Riordan B. Language Policy for Linguistic Minority Students in Japanese Public Schools and Prospects for Bilingualism: The Nikkei Brazilian Case. IULC Working Papers 2005; 5:1-33.

Artigo apresentado em 16/03/2011

Aprovado em 20/07/2011

Versão final apresentada em 31/07/2011 